Dikirim: 19 Juni 2017

Diterbitkan: 1 November 2017

\section{Promosi kesehatan menggunakan gambar dan teks dalam aplikasi WhatsApp pada kader posbindu}

\section{Health promotion using images and text in WhatsApp application on Posbindu health workers}

Nopryan Ekadinata ${ }^{1} \&$ Doni Widyandana ${ }^{2}$

\section{Abstract}

Purpose: This study aimed to determine the effectiveness of educational programs through WhatsApp media on the level of knowledge and satisfaction of learning of Posbindu health workers. Methods: This study was an experimental research on 1 group that consisted of 33 respondents. Two stages of intervention were done with sending an educational text message about diabetes in the first week and picture messages in the second week. The instruments of this study consisted of a knowledge questionnaire and a learning satisfaction questionnaire. The study was conducted on Posbindu health workers with message delivery interventions through WhatsApp. Results: There was a significant change between the mean pre-test and post intervention of text messaging and educational images on knowledge of type 2 diabetes variables, while the delivery of picture messages had the highest mean value of learning satisfaction. Conclusions: Promotion and health education programs through message delivery on WhatsApp effectively can improve the knowledge and satisfaction of learning about type 2 diabetes mellitus.

Keywords: WhatsApp; learning satisfaction; knowledge; education type 2 diabetes mellitus

\footnotetext{
${ }^{1}$ Departemen Perilaku Kesehatan, Lingkungan, dan Kedokteran Sosial, Fakultas Kedokteran, Universitas Gadjah Mada

${ }^{2}$ Fakultas Kedokteran, Universitas Gadjah Mada
} 


\section{PENDAHULUAN}

Diabetes termasuk penyakit 4 besar pada kelompok penyakit tidak menular dengan angka mortalitas 4,5 juta kasus per tahun. Mayoritas penderita diabetes di dunia memiliki klasifikasi diabetes tipe 2. Kasus diabetes secara global dengan kuantitas tertinggi terjadi di negara low and middle income. Penyakit diabetes memiliki implikasi negatif terhadap ekonomi, disabilitas dan hilang atau berkurang masa produktif penderita diabetes. Diabetes adalah penyakit yang berpengaruh langsung dengan dampak penurunan kualitas hidup masyarakat di masa mendatang (1-3).

Prevalensi diabetes melitus mencapai 90\% secara global. Daerah Istimewa Yogyakarta adalah provinsi dengan angka kasus diabetes tipe 2 tertinggi di Indonesia. Penyebab penyakit berkorelasi dengan pengetahuan, dan pola hidup tidak sehat. Sementara genetika dan lingkungan merupakan faktor dominan penyebab diabetes tipe 2 (4-5).

Posbindu adalah unit kegiatan berbasis masyarakat yang bertujuan mendeteksi dini kasus penyakit tidak menular. Keterlibatan masyarakat dalam program Posbindu merupakan esensi utama dalam optimalisasi program pemberdayaan masyarakat (6). Desa Wonokerto adalah wilayah yang sedang mengembangkan program Posbindu bekerjasama dengan pihak Puskesmas dan Kader Posbindu.

Penggunaan internet dan smartphone telah lama diteliti dan terbukti efektif meningkatkan status kesehatan masyarakat. Akses internet memudahkan masya- rakat untuk mencari informasi dan pembelajaran spesifik. Pencarian informasi didominasi oleh peman- fatan internet melalui media smartphone. Tren ini menjadi peluang praktisi kesehatan untuk menyampai- kan informasi kesehatan dengan media sosial (7-8).

WhatsApp adalah aplikasi populer dengan jumlah pengguna tertinggi di dunia. Pengguna WhatsApp dapat memanfaatkan fasilitas mengirim pesan, gambar, video dan video call hingga membuat kelompok diskusi. WhatsApp merupakan aplikasi yang paling sering digunakan dan dengan durasi yang paling lama oleh pengguna smartphone $(9,10)$. Sampai saat ini, belum ada penelitian terkait penggunaan aplikasi chatting sebagai sarana promosi kesehatan. Pemanfaatan aplikasi WhatsApp sebagai media promosi kesehatan dengan topik diabetes tipe 2 perlu dikaji secara ilmiah. Penelitian ini bertujuan untuk mengetahui efektifitas program edukasi tentang diabetes tipe 2 melalui media WhatsApp pada tingkat pengetahuan dan kepuasan belajar kader Posbindu.

\section{METODE}

Penelitian experimental ini menggunakan metode repeated measurement design melalui intervensi berjenjang pada satu kelompok penelitian (11). Core intervensi edukasi penelitian membahas tentang edukasi diabetes tipe 2 melalui WhatsApp group. Intervensi dilakukan selama 2 minggu. Intervensi minggu pertama berupa pesan edukasi diabetes yang dikirimkan melalui WhatsApp group. Intervensi minggu kedua berupa edukasi pesan bergambar. Responden penelitian ini melibatkan 33 kader Posbindu.

Variabel bebas penelitian adalah tingkat pengetahuan diabetes tipe 2 dan nilai kepuasan belajar. Uji efektifitas data sebelum dan setelah intervesi menggunakan repeated measurement Annova. Perbedaan signifikansi kepuasan belajar pada setiap intervensi dianalisis menggunakan independent t-test. Instrumen penelitian menggunakan kuesioner multiple choice untuk menilai pengetahuan diabetes melitus tipe 2 dan kuesioner skala likert untuk menilai kepuasan belajar berdasarkan intervensi.

\section{HASIL}

Tabel 1 menunjukkan kader Posbindu didominasi perempuan dan bependidikan akhir sekolah menegah atas. Pekerjaan utama kader Posbindu pada penelitian ini adalah petani. Empat puluh persen kader menggunakan WhatsApp sebagai media komunikasi selama 3 tahun.

Tabel 1. Ciri responden kelompok intervensi

\begin{tabular}{lc}
\hline Variabel & \% (n=33) \\
\hline Jenis Kelamin & \\
Perempuan $(n=17)$ & 51,52 \\
Laki-laki $(n=16)$ & 48,48 \\
Umur & \\
15-20 (n=14) & 42,42 \\
$21-25(n=15)$ & 45,45 \\
$26-30$ (n=4) & 12,12 \\
Pendidikan Terakhir & \\
SMP (n=6) & 18,8 \\
SMA (n=26) & 78,79 \\
S1 (n=1) & 3,03 \\
Pekerjaan & \\
Pelajar (n=14) & 42,42 \\
Penggiat Desa (n=4) & 12,12 \\
Petani (n=9) & 27,27 \\
Belum Bekerja (n=3) & 9,09 \\
Pegawai Swasta (n=3) & 9,09 \\
Lama Penggunaan Whats App & \\
1 tahun (n=5) & 15,15 \\
2 tahun (n=13) & 39,39 \\
3 tahun (n=14) & 42,42 \\
4 tahun (n=1) & 3,03 \\
\hline
\end{tabular}


Tabel 2 menunjukkan intervensi edukasi melalui pesan bergambar pada WhatsApp memiliki perbedaan skor tertinggi. Hal ini menjelaskan penggunaan pesan bergambar melalui WhatsApp merupakan intervensi paling efektif untuk meningkatkan aspek kognitif kader tentang diabetes melitus tipe 2.

Tabel 2. Rerata dan signifikansi variabel pengetahuan

\begin{tabular}{lcc}
\hline & Rerata Pengetahuan & SD \\
\hline Pre test & $16,15^{\mathrm{a}}$ & 1,85 \\
Intervensi Pesan Teks & $19,12^{\mathrm{ab}}$ & 3,07 \\
Intervensi Pesan & & \\
Bergambar & $22,78^{\mathrm{abc}}$ & 2,07 \\
\hline
\end{tabular}

Keterangan:

-Analisis variabel pengetahuan menggunakan uji repeated measurement Anova

-Notasi yang berbeda dalam kolom yang sama menunjukkan signifikansi $(\mathrm{p}<0,05)$.

Gambar 2 mendeskripsikan kepuasan belajar sebagai parameter efektifitas media pembelajaran melalui WhatsApp. Hasil menunjukkan terdapat perbedaan kepuasaan belajar sebelum intervensi dan setelah intervensi (nilai $\mathrm{p}<0,05$ ).

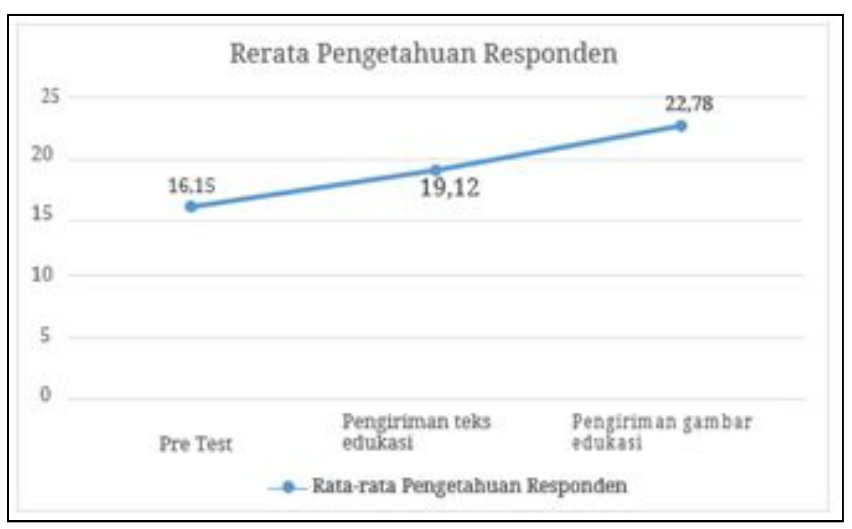

Gambar 1. Grafik perubahan rerata pengetahuan

Nilai kepuasan belajar intervensi program edukasi melalui pesan bergambar pada WhatsApp memiliki nilai rerata tertinggi dibandingkan nilai rerata kepuasan belajar intervensi pengiriman pesan teks.

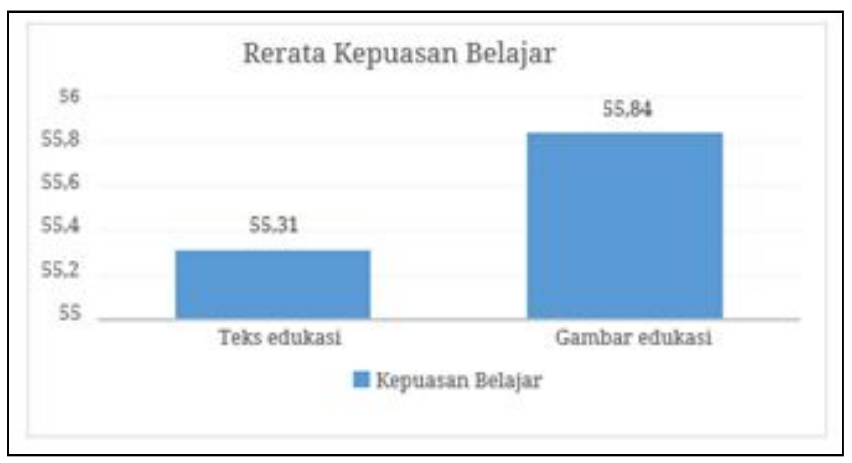

Gambar 2. Perbedaan rerata nilai kepuasan belajar

\section{BAHASAN}

Program edukasi melalui pemanfaatan pengiriman pesan teks dan gambar edukasi tentang diabetes melitus tipe 2 pada aplikasi WhatsApp efektif meningkatkan pengetahuan tentang diabetes melitus tipe 2 . WhatsApp dapat menjadi media peningkatan edukasi kesehatan berbasis. Media sosial merupakan fasilitas komunikasi antara educator kesehatan dan learner dengan sistem diskusi. Kelebihan edukasi menggunakan WhatsApp adalah materi mudah diakses dan cost effective (12).

Penelitian ini menjelaskan efek positif penggunaan gambar dan teks sebagai media edukasi diabetes mellitus tipe 2. Peningkatan skor pengetahuan diabetes merupakan efektif positif penggunaan WhatsApp sebagai media edukasi. Metode pengiriman gambar dan teks edukatif adalah salah satu terobosan yang paling sering diaplikasikan di media sosial sebagai upaya peningkatan aspek kognitif. Program edukasi melalui WhatsApp dapat dioptimalkan melalui pengiriman pesan teks edukasi dan pesan bergambar. Beberapa bukti empirik telah menjelaskan evidence based dampak positif pengiriman pesan gambar dan teks edukatif pada media sosial untuk meningkatkan pengetahuan. Aspek diskusi pada fitur WhatsApp memiliki peluang signifikan dalam meningkatkan minat learner dalam program peningkatan kognitif (10).

Media sosial mudah digunakan untuk mengirimkan pesan, foto, video, panggilan suara, panggilan video hingga wadah informasi komunikasi antar kelompok. Pesan dapat dikirimkan dengan massive, efektif dan real time. Beberapa penelitian menyebutkan bahwa media sosial telah menjadi sumber peningkatan aspek kognitif hingga keterampilan di bidang kesehatan. Internet dan media sosial pada era teknologi saat ini memiliki peluang yang sangat besar dalam pencapaian informasi kesehatan $(13,14)$.

Aspek terpenting dalam pencapaian kesuksesan pembelajaran berbasis media sosial adalah kualitas fasilitator dan target pencapaian pembelajar yang ditentukan oleh learner yang distimulasi dengan penjelasan kurikulum, dan core utama. Aspek fasilitator memiliki nilai fundamental pencapaian learning output dan pencapaian kepuasan belajar. Interaksi fasilitator dan learner merupakan aspek penting lain dalam peningkatan pengetahuan berbasis media sosial (15).

Penelitian menjelaskan dampak positif pesan bergambar dan pesan teks dalam peningkatan kognitif individu tentang kesehatan. Pesan bergambar dan teks merupakan media yang paling sering digunakan pro- 
motor kesehatan untuk mengembangan aspek kognitif dan keterampilan individu dan komunitas.

Pengiriman pesan pendek melalui ponsel lebih efektif dan cost effective dibandingkan kegiatan penyuluhan. Pengiriman pesan pendek dapat dilakukan dalam satu waktu dan mencakup segmentasi masyarakat luas. Penggunaan informasi kesehatan bergambar merupakan aspek potensial penerima pesan dengan tingkat literasi rendah. Penyampaian informasi melalui gambar mampu meningkatkan minat belajar penerima pesan (16-17).

Penelitian ini memanfaatkan WhatsApp sebagai media pengiriman informasi melalui pesan bergambar dan pesan teks. Penentuan pemilihan media pengiriman pesan merupakan aspek penting dalam optimalisasi peningkatan aspek kognitif. Era digital merupakan peluang promotor kesehatan dalam pengembangan kapasitas masyarakat dengan pemanfaatan media daring. Media promosi kesehatan didominasi penyampaian informasi kesehatan berupa gambar dan teks edukasi melalui media daring dan luring. Media gambar dan pesan edukasi adalah media pesan yang paling mudah diterima oleh learner (19).

Pemanfaatan gambar tentang diabetes memiliki efektifitas lebih tinggi dibandingkan teks edukasi. Penyampaian informasi kesehatan melalui gambar lebih potensial dibandingkan melalui teks dari segi output pembelajaran. Informasi kesehatan melalui gambar berhubungan dengan peningkatan minat belajar dan lebih efektif pada orang dengan tingkat literasi rendah. Gambar edukatif meningkatkan respon emosional dan minat belajar spesifik. Perumusan gambar edukatif yang baik akan berimplikasi positif terhadap penerima pesan pada setiap segmentasi usia. Sedangkan, pendidikan kesehatan melalui teks edukatif diterima efektif pada individu dengan tingkat literasi baik serta cenderung tidak berhubungan dengan peningkatan minat belajar penerima pesan (20).

Kepuasan belajar menentukan minat dan upaya eksploratif learner dalam mencapai output pembelajaran mandiri dan optimal. Kepuasan belajar merupakan aspek penting yang harus diperhatikan dalam pemberian metode pembelajaran. Metode pembelajaran efektif sangat ditentukan oleh kepuasan belajar dan berbanding lurus dalam pencapaian target pembelajaran. Parameter kepuasan belajar ditentukan oleh aspek konten materi dan metode pencapaian konten. Aspek lain yang perlu dipertimbangkan adalah kapasitas fasilitator, interaktifitas dan kenyamanan belajar. Metode pembelajaran berbasis WhatsApp memberikan ruang diskusi interaktif (21).
Kepuasan belajar berhubungan erat dengan upaya pencapaian output pembelajaran. Hal ini dipengaruhi oleh aspek fleksibilitas metode pembelajaran, kualitas pembelajaran, kurikulum dan penggunaan media berbasis daring yang mudah digunakan. Media pembelajaran WhatsApp merupakan media edukasi potensial dimana media tersebut merupakan media interaktif antara pengirim dan penerima pesan (22).

\section{SIMPULAN}

WhatsApp adalah media edukasi diabetes tipe 2 yang efektif. Pengiriman pesan bergambar memiliki nilai rerata pengetahuan dan kepuasan lebih tinggi dibandingkan pesan teks.

\section{Abstrak}

Tujuan: Penelitian ini bertujuan mengetahui efektifitas program edukasi tentang diabetes tipe 2 melalui media WhatsApp pada tingkat pengetahuan dan kepuasan belajar kader Posbindu. Metode: Penelitian ini merupakan penelitian eksperimen pada 1 kelompok yang terdiri dari 33 responden. Intervensi terdiri dari 2 tahap, yakni: pengiriman pesan teks edukasi tentang diabetes pada minggu pertama dan pesan bergambar pada minggu kedua. Instrumen penelitian ini terdiri dari kuesioner pengetahuan dan kuesioner kepuasan belajar. Penelitian dilakukan pada kader Posbindu dengan intervensi pengiriman pesan melalui WhatsApp. Hasil: Terdapat perubahan signifikan antara rerata nilai pre test, post intervensi pengriman pesan teks dan post intervensi pengiriman gambar edukasi pada variabel tentang pengetahuan diabetes tipe 2 . Pengiriman pesan bergambar merupakan intervensi paling signifikan dalam meningkatkan pengetahuan dan kepuasan belajar responden. Simpulan: Program promosi dan edukasi kesehatan melalui pengiriman pesan bergambar pada WhatsApp efektif meningkatkan pengetahuan dan kepuasan belajar tentang diabetes melitus tipe 2 .

Kata kunci: WhatsApp; kepuasan belajar; pengetahuan; edukasi diabetes tipe 2 


\section{PUSTAKA}

1. Soewondo, P., Ferrario, A., \& Tahapary, D. L. Challenges in diabetes management in Indonesia: a literature review. Globalization and health. 2013;9(1), 1.

2. Kemenkes RI Riset Kesehatan Dasar Tahun 2013. Badan Litbangkes. Jakarta. 2013.

3. WHO. Global Report On Diabetes. WHO Library Cataloguing - in Publication Data. France. 2016.

4. Wu, Y., Ding, Y., Tanaka, Y., \& Zhang, W. Risk factors contributing to type 2 diabetes and recent advances in the treatment and prevention. International journal of medical sciences. 2014;11(11), 1185

5. Kemenkes RI. Situasi dan Analisis Diabetes. Pusat Data dan Informasi Kementerian Kesehatan RI. Jakarta. 2014

6. Kemenkes RI. Petunjuk Teknis Pos Pembinaan Terpadu Penyakit Tidak Menular. Direktorat Jendral Pengendalian Penyakit Tidak Menular. Jakarta. 2012.

7. Korp, P. Health on the Internet: implications for health promotion. Health education research. 2006;21(1), 78-86.

8. Laranjo, L., Arguel, A., Neves, A. L., Gallagher, A. M., Kaplan, R., Mortimer, N., Lau, A. Y. The influence of social networking sites on health behavior change: a systematic review and meta-analysis. Journal of the American Medical Informatics Association, amiajnl. 2014.

9. Montag, C., Błaszkiewicz, K., Sariyska, R., Lachmann, B., Andone, I., Trendafilov, B., \& Markowetz, A. Smartphone usage in the 21st century: who is active on WhatsApp?. BMC research notes. 2015;8(1), 331

10. Boulos, M. N., Giustini, D. M., \& Wheeler, S. Instagram and WhatsApp in Health and Healthcare: An Overview. Future Internet; 2016;8(3), 37.

11. Salazar, L. F., Crosby, R. A., \& DiClemente, R. J. Research methods in health promotion. John Wiley \& Sons. 2015.

12. Alanzi, T. M., Bah, S., Jaber, F., Alshammari, S., \& Alzahrani, S. Evaluation of a Mobile Social Networking Application for Glycaemic Control and Diabetes Knowledge in Patients with Type 2 Diabetes: A Randomized Controlled Trial Using
WhatsApp. In Qatar Foundation Annual Research Conference Proceedings 2016;1, p. HBPP2533). Qatar: HBKU Press.

13. Gold, J., Pedrana, A. E., Sacks-Davis, R., Hellard, M. E., Chang, S., Howard, S., ... \& Stoove, M. A. A systematic examination of the use of online social networking sites for sexual health promotion. BMC public health. 2011;11(1), 583

14. Bennett, G. G., \& Glasgow, R. E. The delivery of public health interventions via the Internet: actualizing their potential. Annual review of public health. 2009;30, 273-292.

15. Sun, P. C., Tsai, R. J., Finger, G., Chen, Y. Y., \& Yeh, D. What drives a successful e-Learning? An empirical investigation of the critical factors influencing learner satisfaction. Computers \& education. 2008;50(4), 1183-1202.

16. Paechter, M., Maier, B., \& Macher, D. Students' expectations of, and experiences in e-learning: Their relation to learning achievements and course satisfaction. Computers \& education. 2010;54(1), 222-229.

17. Hussein, W. I., Hasan, K., \& Jaradat, A. A. Effectiveness of mobile phone short message service on diabetes mellitus management; the SMS-DM study. Diabetes research and clinical practice. 2011;94(1), e24-e26.

18. Park, J., \& Zuniga, J. Effectiveness of using picture-based health education for people with low health literacy: An integrative review. Cogent Medicine, (just-accepted), 2016.1264679.

19. Lupton, D. Health promotion in the digital era: a critical commentary. Health promotion international. 2015;30(1), 174-183.

20. Houts, P. S., Doak, C. C., Doak, L. G., \& Loscalzo, M. J. The role of pictures in improving health communication: a review of research on attention, comprehension, recall, and adherence. Patient education and counseling. 2006;61(2), 173-190.

21. Wu, Y. C., Hsieh, L. F., \& Lu, J. J. What's The Relationship between Learning Satisfaction and Continuing Learning Intention?. Procedia-Social and Behavioral Sciences. 2015;191, 2849-2854.

22. Sun, P. C., Tsai, R. J., Finger, G., Chen, Y. Y., \& Yeh, D. What drives a successful e-Learning? An empirical investigation of the critical factors influencing learner satisfaction. Computers \& education. 2008;50(4), 1183-1202. 
